\title{
INFLUENCE OF THE INFILL ON THE TENSILE STRENGTH AND THE ECONOMIC FACTORS OF 3D PRINTING
}

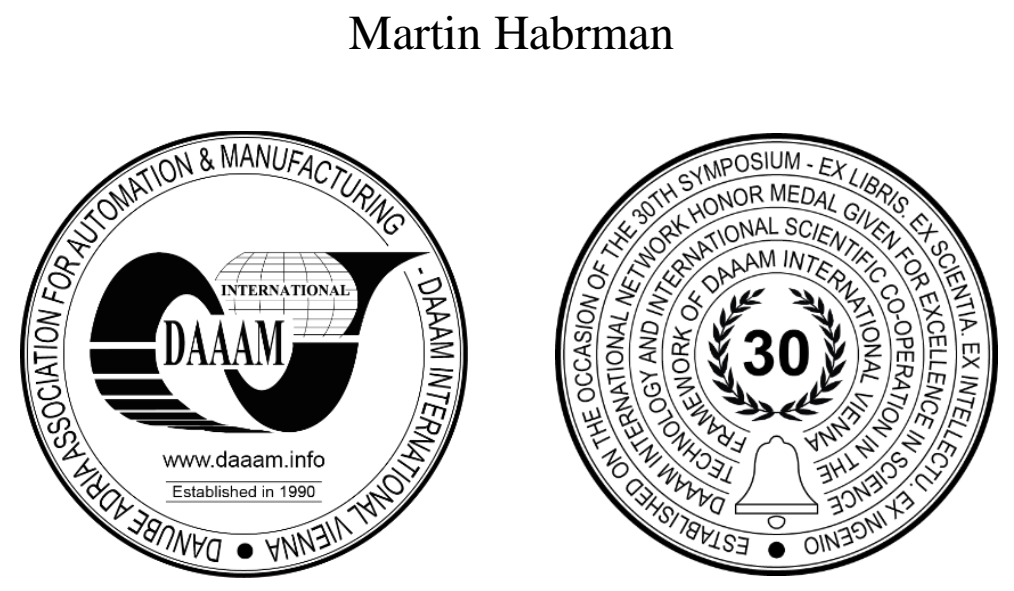

This Publication has to be referred as: Habrman, M[artin] (2019). Influence of the Infill on the Tensile Strength and the Economic Factors of 3D Printing, Proceedings of the 30th DAAAM International Symposium, pp.1056-1060, B. Katalinic (Ed.), Published by DAAAM International, ISBN 978-3-902734-22-8, ISSN 1726-9679, Vienna, Austria DOI: $10.2507 / 30$ th.daaam.proceedings.147

\begin{abstract}
This work deals with the infill of 3D printed parts. The goal of this work is to provide recommendations on how much a part should be filled. The recommendation is supported by experiment. The selected load is tensile. Therefore, the geometry of the samples was based on the standard CSN EN ISO 527-2. Five densities of infill were selected to determine an infill rate from 0 to $100 \%$. In addition to the tensile strength values for each sample, the work also considers economic factors. Characteristic graphs for this issue were constructed at the end of the work. They give an overview of how tensile strength, as well as time, and the cost of 3D printing, change with increasing densities of infill.
\end{abstract}

Keywords: 3D print; Tensile strength test; Fill density; Lattice structure

\section{Introduction}

The popularity of 3D printing is constantly increasing and the related amounts of 3D parts too. 3D printed parts can be described by mechanical properties. This experiment is focused on tensile strength. Every 3D printed part consists of a shell and an infill. The shell may be made from several walls. The infill is something that connects the walls. Then comes the question, how much should the part be filled. The density of infill is given in percent. What percent to choose? How much will it affect tensile strength? The experiment focuses on these questions. The percentage of infill and the effect of fill density on other properties will be researched for one type of infill.

For the experiment, the grid infill was selected. The possibility of filling the part is from 0 to 100 percent. The experiment is tries to cover this range with five infills. At the end of the work I also considered the costs of the consumed material and printing time. 


\section{Samples}

The Ultimaker S5 printer was selected to print the part. This printer uses FDM (Fused Deposition Modelling) for printing. FDM is one of the most popular 3D printing methods. For this reason, it was chosen for this experiment. The principle of FDM is based on the application of molten plastic. The molten plastic is applied through a nozzle with an exact diameter. The first layer is deposited on the hot bed, the next layers on the previous plastic layers. This method is often called layer by layer printing. The direction of printing is from bottom to top. [2], [13]

Nowadays I can choose from a wide assortment of materials. The most commonly used material was selected for this experiment, PLA (Polylactic acid). In 2010, PLA had the second highest consumption volume of any bioplastic in the world. The material manufacturer was the same as for the 3D printer - Ultimaker. [6], [15]

The shape of the sample is shown in Fig. 1.

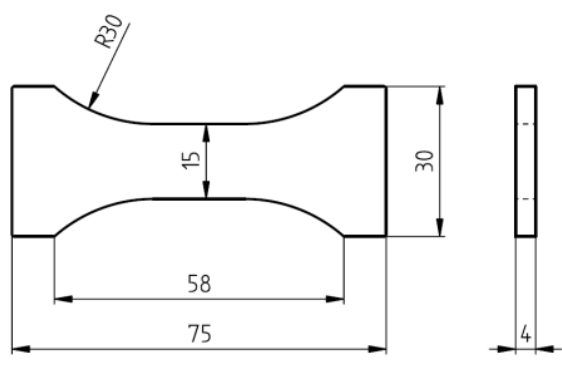

Fig. 1. Sample shape

The shape of the sample was based on ČSN EN ISO 527-2, type 1BA. The length of the sample is only $75 \mathrm{~mm}$, still acceptable by the norm. Apart from the width, every other dimension was retained. The width was increased by three times. The reason is the transfer of the tensile load by more infill.

The tensile strength is also dependent on the deposition process of the layer. The deposition procedure can be seen in Fig. 2. The trajectory has not been changed from the default setting in the Cura slicer. [14]

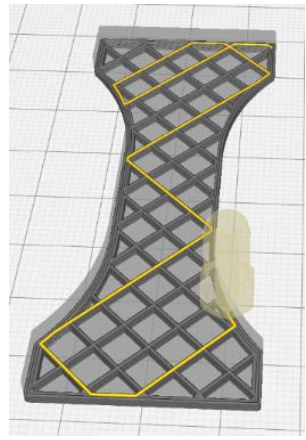

Infill $20 \%$

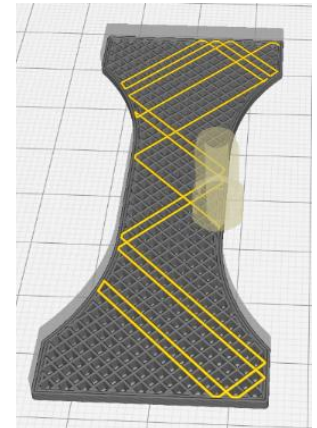

Infill $60 \%$

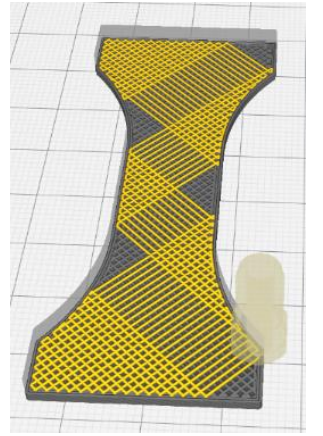

Infill $100 \%$

Fig. 2. Deposition of the infill

Other values of print settings are given in Table 1. Values in the table are the same for the initial layer and other layers.

\begin{tabular}{|l|r|c|}
\hline Layer height & 0.1 & {$[\mathrm{~mm}]$} \\
\hline Layer width & 0.4 & {$[\mathrm{~mm}]$} \\
\hline Nozzle temperature & 210 & {$\left[{ }^{\circ} \mathrm{C}\right]$} \\
\hline Bed temperature & 60 & {$\left[{ }^{\circ} \mathrm{C}\right]$} \\
\hline
\end{tabular}

Table 1. Printing setting

The width of the sample shell is $0.8 \mathrm{~mm}$. It is equal to two walls. Samples of the same infill density were printed on the same bed. 25 simples were printed for the print setting parameters. One infill density was printed five times. Selected infill densities including properties are given in Table 2. [1] 


\begin{tabular}{|l|c|c|c|c|c|c|}
\hline Infill density & {$[\%]$} & $\mathbf{2 0}$ & $\mathbf{4 0}$ & $\mathbf{6 0}$ & $\mathbf{8 0}$ & $\mathbf{1 0 0}$ \\
\hline Sample weight & {$[\mathrm{g}]$} & 2 & 4 & 5 & 6 & 8 \\
\hline Consumption of material & {$[\mathrm{m}]$} & 0.29 & 0.47 & 0.64 & 0.82 & 0.99 \\
\hline Print time & {$[\mathrm{min}]$} & 21 & 30 & 39 & 49 & 59 \\
\hline \multirow{2}{*}{ Print time - infill } & {$[\mathrm{min}]$} & 10 & 20 & 29 & 39 & 48 \\
& & $52[\%]$ & $67[\%]$ & $75[\%]$ & $79[\%]$ & $82[\%]$ \\
\hline \multirow{2}{*}{ Print time - wall } & {$[\mathrm{min}]$} & 7 & 7 & 7 & 7 & 7 \\
& & $35[\%]$ & $24[\%]$ & $18[\%]$ & $15[\%]$ & $13[\%]$ \\
\hline \multirow{2}{*}{ Print time - others } & {$[\mathrm{min}]$} & 2 & 2 & 2 & 2 & 2 \\
& & $13[\%]$ & $9[\%]$ & $7[\%]$ & $6[\%]$ & $5[\%]$ \\
\hline
\end{tabular}

Table 2. Sample properties

Table 2 shows how the consumption of material and print time increases with increasing infill density.

\section{Determination of tensile strength}

This can be divided into two steps. Samples were analysed in the first step. During the measurement, it was found that the crack was not only at the narrowest place, as can be seen in Fig. 3. [10]

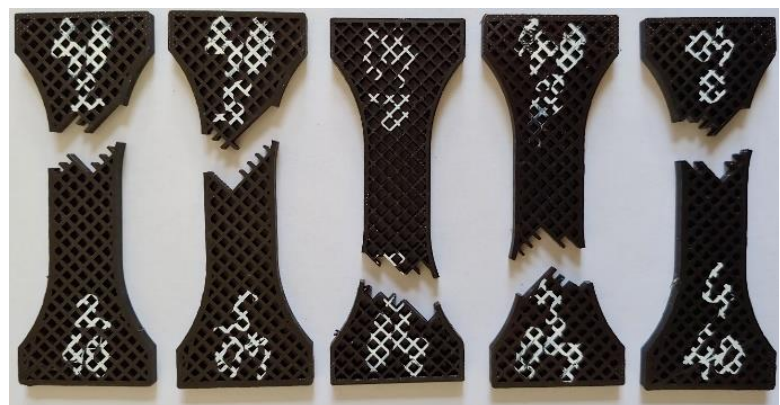

Fig. 3. Cracked samples with infill $40 \%$

The next part of the work was analysis of the crack. What affects the crack and where does it lead? The crack always goes through the infill and two walls. The crack probably starts in the infill, the smallest cross-section. It continues to the walls. Finally, the walls are torn too. The analysed cross-section is shown in Fig. 4. [9], [7]

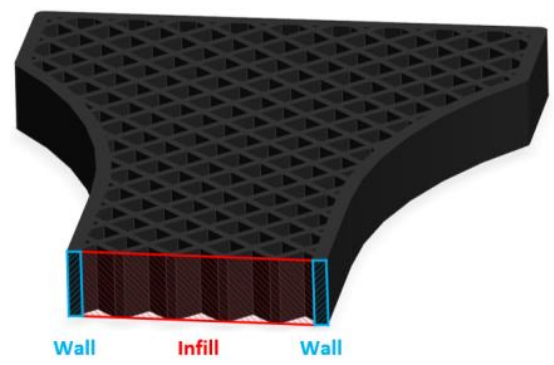

Fig. 4. Cross- section of sample

The second step investigates how much stress the walls can transfer. The wall samples were printed under the same printing conditions. The walls were printed from bottom to top. The material was deposited in the longitudinal direction. Five walls were printed. [3], [12]

The measurement conditions for the samples and the walls were the same. Samples were measured on a Zwick Roell Z250 and wall measurements on a Zwick / Roell Z005. The displacement and force were measured. All samples behaved as fragile materials. For this reason, the maximum force which the sample can transfer was selected. Tensile strength was calculated only for information purposes. The cross-section is the same as in Fig. 4. The measured values are shown in columns under the label - Sample in Table 3. 


\begin{tabular}{|c|c|c|c|c|c|}
\hline & \multicolumn{3}{|c|}{ Sample } & \multicolumn{2}{|c|}{ Sample without walls } \\
\hline & Displacement & Force & Stress & Force & Stress \\
\hline & [mm] & {$[\mathbf{N}]$} & [MPa] & {$[\mathbf{N}]$} & [MPa] \\
\hline Infill 20 [\%] & 0.49 & 369.3 & 6.0 & 143.7 & 2.2 \\
\hline Infill 40 [\%] & 0.51 & 497.9 & 8.6 & 272.2 & 4.8 \\
\hline Infill 60 [\%] & 0.53 & 729.9 & 12.5 & 504.2 & 8.7 \\
\hline Infill 80 [\%] & 0.52 & 1130.9 & 18.9 & 905.2 & 15.1 \\
\hline Infill 100 [\%] & 0.43 & 1736.8 & 28.9 & 1511.2 & 25.1 \\
\hline Wall & 2.18 & 112.8 & 1.88 & & \\
\hline
\end{tabular}

Table 3. Sample values

Next, the force without walls was evaluated. The goal was to eliminate the influence of the walls. This evaluation is not totally accurate in terms of force effect. For the sample, the stress leads around the perimeter by the walls. For the wall samples, the force is in the axis. The force transmitted by the sample without the walls was determined as:

Force $=$ Force transmitted by sample $-2 *$ Force in the wall

The calculated values are shown in columns under the label - sample without walls in Table 3. [8]

\section{Evaluation}

The printing time and cost of material were included in the total evaluation. Also, economic factors will have a decisive influence. They will decide if the technical parameters are acceptable

The filament in the spool is Ultimaker PLA - M0751 Black 750-211399, PLA plastic, $2.85 \mathrm{~mm}, 750 \mathrm{~g}$. There is approximately $90 \mathrm{~m}$ of filament in one spool. The price of one spool is approximately 40 euros. From these values it is possible to calculate the price per $1 \mathrm{~m}$ of material.

$$
\text { price for } 1[\mathrm{~m}] \text { material }=\frac{40[\mathrm{eur}]}{90[\mathrm{~m}]} \cong 0.44[\mathrm{eur} / \mathrm{m}]
$$

If the amount of consumed material per sample is known, it is possible to calculate the price per sample. How much the increasing force influences the printing time and the price can be seen in the graphs in Fig. 5. [4]
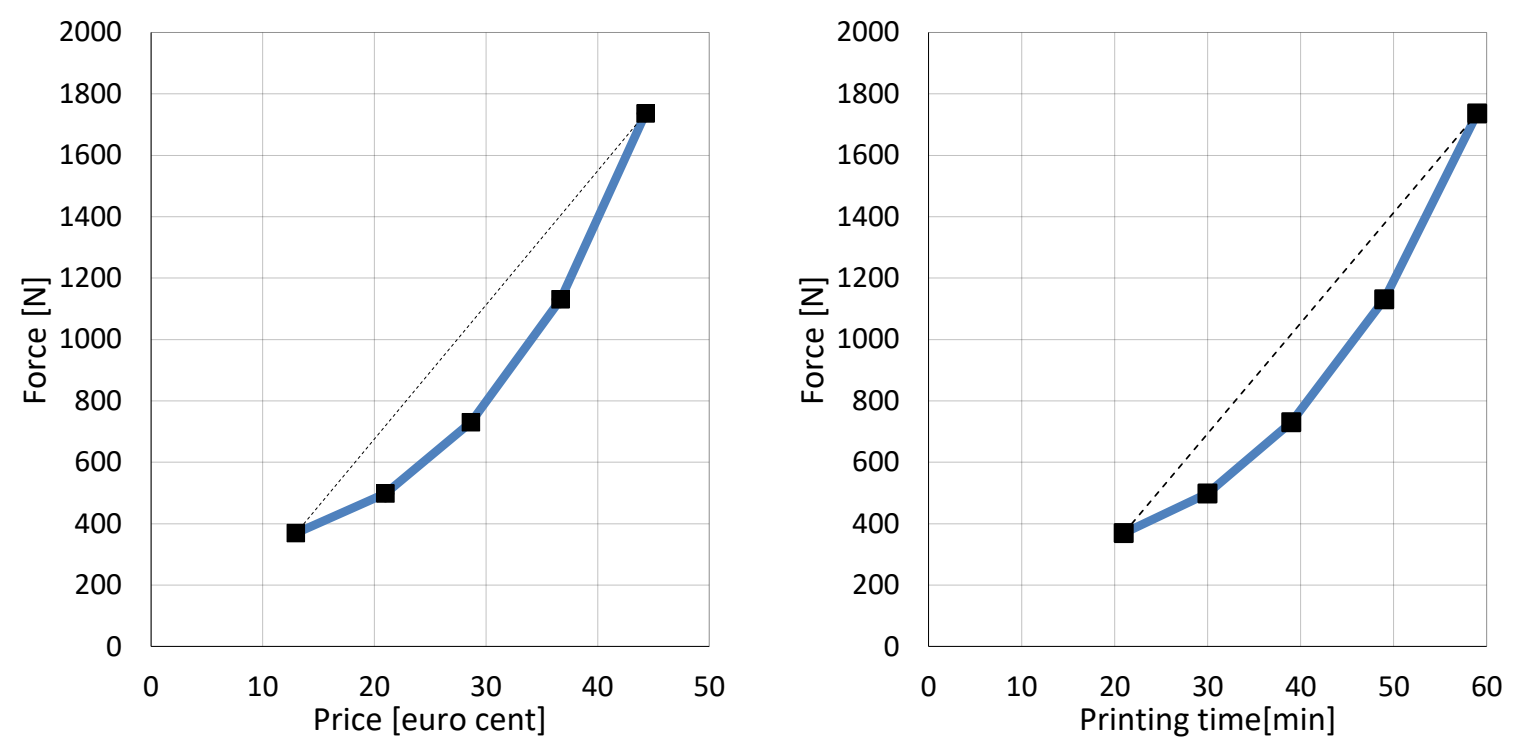

Fig. 5. Graphs of overall evaluation

The points gradually rise according to the sample infill percentage. The least force is in the $20 \%$ of infill and the highest in the $100 \%$ of infill. For better illustration, these points are connected by the line. The graphs in Fig. 5 show the exponential dependence between transferred tensile force and economic factors. At the start of the graphs, increasing the percent of the infill has a small effect on strength. Economic factors are growing faster. At the end of the graph in Fig. 5, the situation is reversed. Based on these properties, it is possible to say the following. If tensile strength is not required from the part, use only a little infill. Just enough necessary to print the highest layers. On the other hand, for high tensile strength it is good to use the largest possible percentage of infill. [5], [11] 


\section{Conclusion}

The experiment deals with the influence of the infill on the tensile strength and the economic factors of 3D printing. The goal was achieved. Charts of recommendations for using 3D printing infill were presented.

The infill range was covered by 5 samples. The shape of the sample was based on the norm ČSN EN ISO 527-2. The shape of the sample was adjusted for analysing the infill. For analysing the force, it included the effect of the walls. Tensile strength was determined only for information purposes. The graphs at the end of this article describe the problem of $3 \mathrm{D}$ printing with infills.

\section{Acknowledgments}

The present contribution was supported from ERDF "Research of additive technologies for future applications in the machinery industry - RTI plus" (No. CZ.02.1.01/0.0/0.0/18_069/0010040).

\section{References}

[1] Polák, R.; Sedláček, F. \& Ráž, K. (2017). Determination of FDM printer settings with regard to geometrical accuracy. In Proceedings of the 28th DAAAM International Symposium, Zadar, ISSN: 1726-9679, ISBN 978-3902734-11-2, Katalinic, B. (Ed.), pp. 0561-0566, DAAAM International, Vienna, DOI: 10.2507/28th.daaam.proceedings.079

[2] Sedláček, F. \& Lašová, V. (2018). Additive Manufacturing of PA6 with Short Carbon Fibre Reinforcement using Fused Deposition Modelling, Materials Science Forum (MSF), Vol. 2018, No. 8, PP 26-31, ISSN 0255-5476

[3] Marek, V. (2016). Basic Research of thermal transfer simulations, In Proceedings of the 27th DAAAM International Symposium, Mostar, ISSN: 1726-9679, Katalinic, ISBN 978-3-902734-08-2, B. (Ed.), pp. 0578-0585, DAAAM International, Vienna, DOI: 10.2507/27th.daaam.proceedings.085

[4] Zahálka, M. (2018). Stability of the brass cups forming process. In Proceedings of the 29th DAAAM International Symposium, Zadar, ISSN: 1726-9679, ISBN 978-3-902734-20-4, Katalinic, B. (Ed.), pp. 0435-0439, DAAAM International, Vienna, DOI: 10.2507/29th.daaam.proceedings.064

[5] Hynčík, L.; Maňas, J.; Špička, J.; Špirk, S. \& Kovář, L. (2014). Development of 6 Years Old Child Virtual Model by Automatic Scaling, In SAE Technical Papers, Vol. 2014, No.3 pp. 1-8. , ISSN: 0148-719, DOI: 10.4271/2014$01-2028$

[6] Kalina, T.; Sedláček F. \& Kroupa T. (2018). Determination of cohesive parameters for mode I of epoxy adhesive. In Proceedings of the 29th DAAAM International Symposium, Zadar, ISSN 1726-9679, ISBN 978-3-902734-20-4, Katalinic, B. (Ed.), pp.0746-0751, DAAAM International, Vienna, DOI:10.2507/29th.daaam.proceedings.108

[7] Ráž, K.; Zahálka, M.; Chval \& Z., Kučeová, L. (2017). Analysis of Weld Line Influence on Strength of Nylon Parts. Manufacturing Technology, Vol. 17, No. 4, pp. 561-565. ISSN: 1213-2489

[8] Chval, Z. \& Ráž, K. (2016). Effect of heat load on mechanical forging press, In Proceedings of the 27th DAAAM International Symposium, Mostar, ISSN: 1726-9679, ISBN: 978-3-902734-08-2, Katalinic, B. (Ed.), pp. 344-348, DAAAM International, Vienna, DOI: 10.2507/27th.daaam.proceedings.050

[9] Markovičová, L. \& Zatkaliková, V. (2016). Composite Materials Based on pa Reinforced Glass, Fibers, In Materials Today: Proceedings, Vol. 3, pp. 1056-1059, E-ISSN: 2214-7853

[10] Markovičová, L.; Hurlatová, L.; Zatkaliková, V. \& Garbacz, T. (2014). Evaluation of composite structures by light microscopy and image analysis, Manufacturing Technology, Vol. 14, No. 3, pp. 351-355, ISSN 1213-2489

[11] Ráž, K. \& Chval, Z. (2017). Influences of pressures and cycle times on properties of final plastic product from HDPE. International Conference on Mechanical, System and Control Engineering (ICMSC). New York: Institute of Electrical and Electronics Engineers Inc., pp. 1-5, ISBN: 978-1-5090-6530-1

[12] Yang, H; Wang, B. \& Ma, L. (2019). Mechanical properties of 3D double-U auxetic structures, International Journal of Solids and Structures, Vol. 2019, No. 7, pp 180-180, ISSN: 00207683, DOI: 10.1016/j.ijsolstr.2019.07.007

[13] Le Duigou, A.; Barbé, A.; Guillou, E. \& Castro, M. (2019). 3D printing of continuous flax fibre reinforced biocomposites for structural applications, Materials and Design, Vol. 2019, No. 10, Volume 180, ISSN: 02641275

[14] Gordelier, T.J.; Thies, P.R.; Turner, L. \& Johanning, L. (2019). Optimising the FDM additive manufacturing process to achieve maximum tensile strength: a state-of-the-art review, Rapid Prototyping Journal; Vol. 2019, No. 7, ISSN: 13552546

[15] Caminero, M.Á.; Chacón, J.M.; García-Plaza, E.; Núñez, P.J.; Reverte, J.M. \& Becar, J.P. (2019). Additive manufacturing of PLA-based composites using fused filament fabrication: Effect of graphene nanoplatelet reinforcement on mechanical properties, dimensional accuracy and texture, Polymers, Vol. 2019, No. 5, ISSN: 20734360 